Recepción: 30/ 11/ 2016

Aceptación: 15 / 02/ 2017

Publicación: 06/ 03/2017

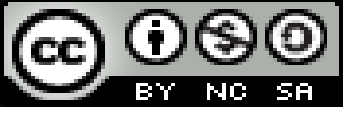

Ciencias de la salud

Artículo de investigación

\title{
Enfermedades bucodentales en embarazadas del Centro de Salud Portoviejo, Ecuador
}

\section{Oral diseases in pregnant women at the Portoviejo Health Center, Ecuador}

\section{Doenças bucais em centro de saúde grávida Portoviejo, Equador}

\author{
Freddy A. Ávila Chica ${ }^{\mathrm{I}}$ \\ freddyavilach@gmail.com \\ Julio C. Jimbo Mendoza ${ }^{\mathrm{II}}$ \\ juliojimbomendoza@gmail.com \\ Alba M. Mendoza Castro III \\ albamariamc@hotmail.com
}

\section{Correspondencia: freddyavilach@gmail.com}

\begin{abstract}
${ }^{I}$ Magister en Salud Publica Mención Gerencia de los Servicios de Salud, Doctor en Odontología, Diploma Superior en Educación Universitaria por Competencias, Docente de la Universidad Laica Eloy Alfaro de Manabí, Manta, Ecuador.
\end{abstract}

\footnotetext{
${ }^{\text {II }}$ Magister en Gerencia de Salud para el Desarrollo Local, Especialista en Gerencia y Planificación Estratégica en Salud, Doctor en Odontología, Diploma Superior en Odontología Integral, Diploma Superior en Desarrollo Local y Salud, Docente de la Universidad Laica Eloy Alfaro de Manabí, Manta, Ecuador.
}

III Odontóloga Especialista en Endodoncia, Magister en Gerencia de Salud para el Desarrollo Local, Odontóloga, Docente de la Universidad Laica Eloy Alfaro de Manabí, Manta, Ecuador. 


\title{
Resumen
}

El embarazo constituye un proceso natural que provoca una serie de cambios fisiológicos, patológicos y psicológicos que las convierten en pacientes especiales que demandan cuidados exclusivos. Se realizó un estudio descriptivo transversal con el objetivo de identificar las enfermedades bucodentales en mujeres embarazadas que acudieron al Centro de Salud Portoviejo, Ecuador. La población de estudio fue 96 mujeres embarazadas, que acudieron a consulta. Luego de procesada la información, se obtuvo un predominio de caries dental, seguida de la periodontitis; la higiene bucal deficiente fue el factor de riesgo que más influyó. De este estudio se infirió que la realización de trabajos educativos, dirigidos a mejorar el estado de salud bucal constituye una necesidad del momento actual.

Palabras clave: embarazadas; enfermedades bucodentales; atención odontológica.

\begin{abstract}
Pregnancy is a natural process that causes a series of physiological, pathological and psychological changes that make them special patients that demand exclusive care. A cross sectional descriptive study was carried out to identify oral diseases in pregnant women who attended the Portoviejo Health Center, Ecuador. The study population was 96 pregnant women, who came for consultation. After the information was processed, a predominance of dental caries was obtained, followed by periodontitis, poor oral hygiene was the most influential risk factor. From this study it was inferred that the accomplishment of educative works, directed to improve the state of oral health is a necessity of the present moment.
\end{abstract}

Keywords: pregnant women; oral diseases; dental care.

\section{Resumo}

A gravidez é um processo natural que provoca uma série de alterações fisiológicas, patológicas e psicológicos que os tornam pacientes de cuidados especiais que requerem exclusivo. Um estudo descritivo transversal foi realizado para identificar doenças orais em mulheres grávidas que frequentam Health Center Portoviejo, Equador. A população do estudo foram 96 mulheres grávidas que frequientaram a clínica. Depois que a informação processada, uma prevalência de cáries dentárias, periodontites, seguido por má higiene oral foi obtido foi o factor de risco mais 
influente. Este estudo foi inferir que realizar trabalho educativo, que visa melhorar a saúde oral é uma necessidade do momento.

Palavras chave: grávida; doenças orais; cuidados dentários.

\section{Introducción}

El embarazo constituye un proceso natural y sublime en la vida de una mujer, etapa que está acompañada de una serie de cambios fisiológicos, patológicos y psicológicos que las convierten en pacientes especiales que demandan cuidados exclusivos. La atención de las gestantes desde las primeras sospechas o indicios de embarazo, es importante para garantizar el desarrollo normal y su salud en general. ${ }^{1,2}$

El embarazo no es una enfermedad y no debe ser tratado como tal, aunque existen algunas consideraciones especiales para el tratamiento dental de las gestantes para prevenir la aparición de enfermedades bucales, fundamentalmente las relacionadas con la falta de higiene bucal adecuada que se vinculan con los cambios hormonales característicos de este período. ${ }^{3,4 .}$

En la actualidad, se hace imprescindible el análisis integral de los problemas de salud. El tener en consideración este concepto permite hacer importante hincapié en la atención odontológica de la gestante, pues suceden cambios bucales dependientes de los que suceden en su organismo y que son resultado de un conjunto de factores que influyen en la salud bucal. El aumento de la secreción de estrógenos, aumenta enormemente la vascularización, lo cual hace más susceptible la gíngiva a la acción de los irritantes locales causando inflamación. También se plantea el aumento de mediadores químicos como las prostaglandinas, así como una alteración del sistema fibrinolítico. ${ }^{5}$

El odontólogo, debe conocer adecuadamente los cambios que pueden suceder en el organismo de la mujer embarazada, para así saber hacia dónde dirigir la atención estomatológica, teniendo en cuenta las individualidades de cada una de las gestantes.

En el Ecuador, las enfermedades bucodentales se encuentran entre las enfermedades de mayor demanda de atención de los servicios del país, y la caries dental es una de las patologías más prevalentes, que continúan siendo un problema de salud pública y afecta considerablemente a la población y especialmente a la infantil. ${ }^{6}$ 
La Odontología, como una respuesta científico técnica hace presencia desde 1967 dentro de la estructura del Ministerio de Salud Pública, como División Nacional de Salud Bucal y se expresa a través de la promoción de servicios, producción de conocimientos, en estrecha relación con actividades de investigación, planificación, capacitación, monitoreo y evaluación. Para la implementación de los planes y programas se publican las Normas para los Servicios de Odontología en abril de 1978, mediante Registro Oficial № 266 del 31 de Enero de 1977. ${ }^{6}$

La salud bucal es responsabilidad directa del Programa Nacional de Salud Bucal, en el cual se planifica, norma y gerencia. La prestación de servicios de salud bucal se realiza en establecimientos organizados de acuerdo al grado de complejidad en tres niveles de atención entre ella están las embarazadas. ${ }^{6}$

Por los riesgos descritos que presuponen las alteraciones del embarazo y la importancia que le concede nuestro país a la atención odontológica de la gestante, es que nos propusimos realizar esta investigación en el Centro de Salud No 1 de la ciudad de Portoviejo.

\section{Material y métodos}

Se realizó un estudio descriptivo transversal con el objetivo de identificar las enfermedades bucodentales en mujeres embarazadas que acudieron al centro de salud Portoviejo, Ecuador.

La población de estudio estuvo conformada por las 96 embarazadas que acudieron a consulta.

Instrumentos y técnicas utilizadas:

- Encuestas dirigidas a las pacientes embarazadas del Centro de Salud Portoviejo.

- Observación de las pacientes embarazadas del Centro de Salud Portoviejo.

- Ficha clínica odontológica.

Como principales variables analizadas figuraron: hallazgos clínicos (enrojecimiento de las encías, inflamación gingival, gingivitis, periodontitis, mal oclusión) caries, obturados, pérdida dentaria, frecuencia de atención en el centro de salud, frecuencia del cepillado, uso de fármacos entre otras. Se utilizó el porcentaje como medida de resumen. 


\section{Resultado y discusión}

Tabal 1: Hallazgos clínicos, enfermedad periodontal en embarazadas del Centro de Salud. Portoviejo, Ecuador.

\begin{tabular}{|c|c|c|c|}
\hline & HALLAZGOS CLINICOS & $\mathbf{F}$ & $\%$ \\
\hline a) & Enrojecimiento de las encías & 16 & 17 \\
\hline b) & Inflamación gingival & 18 & 19 \\
\hline c) & Gingivitis & 12 & 13 \\
\hline d) & Periodontitis & 30 & 31 \\
\hline e) & Mal oclusión & 19 & 20 \\
\hline & Total & 95 & 100 \\
\hline
\end{tabular}

En la tabla 1, se observa que el $31.0 \%$ de las embarazadas atendidas presentaban periodontitis, seguida de mal oclusión (20.0\%), inflamación gingival (19.0\%), gingivitis $(13.0 \%)$ y $17.0 \%$ presentaba un enrojecimiento de las encías. La higiene bucal deficiente fue el factor de riesgo que prevaleció en este estudio

La periodontitis es una inflamación destructiva del periodonto que afecta aproximadamente al $30 \%$ de las mujeres en edad fértil. El proceso implica la formación y acumulación de bio-film oral o placa bacteriana dentro de la encía. Las bacterias y sus toxinas estimulan una respuesta inflamatoria crónica, lo que provoca una destrucción progresiva del periodonto y la aparición de bolsas que el individuo ya no puede higienizar y que necesitan de tratamiento profesional. Si esto no se realiza, finalmente los dientes pueden llegar a perderse. ${ }^{7}$

Los resultados obtenidos en la investigación efectuada por García Morales G. (2016), en cuanto al estado periodontal, una mujer de las 88 presentaron bolsa periodontal, no se encontró afectación que ocasionara movilidad de la pieza dentaria. ${ }^{8}$ 
Al realizar el examen bucal a las pacientes embarazadas el $61.0 \%$ presentaron caries dental, $33.0 \%$ presentaron tratamiento conservador (obturación), solamente el $6 \%$ la pérdida dentaria fue ocasionada por la presencia de caries dental.

El riesgo de padecer caries dental se asoció significativamente con el consumo de hidratos de carbono en otro estudio hecho por De Aguiar T y colaboradores. ${ }^{9}$ La dieta pone a disposición de los microorganismos de la placa dentobacteriana el sustrato metabólico, lo que sumado a los malos hábitos de higiene bucal pueden dar lugar a un aumento de la incidencia de caries dental en el embarazo, sin que sea necesaria, además, la existencia de un esmalte supuestamente debilitado por los cambios gestacionales. ${ }^{10}$ La caries dental se identificó como la enfermedad que más afectó a las gestantes con el 47,8\% en un estudio realizado en el Policlínico Pedro Díaz Coello de Holguín a un total de 395 embarazadas que acudieron a la consulta en el período de enero de 2014 a enero de 2015 por Méndez de Varona Y et al. (2016), lo cual coincidió con nuestro estudio.

Tabla 2: Frecuencia de veces atendida en el centro de salud.

\begin{tabular}{|l|l|c|c|}
\hline & \multicolumn{1}{|c|}{$\begin{array}{c}\text { Número de Veces } \\
\text { Atendida }\end{array}$} & PACIENTES & N \\
\hline a) & Una vez & 44 & 47 \\
\hline b) & Varias veces & 51 & 53 \\
\hline & TOTAL & 95 & 100 \\
\hline
\end{tabular}

Como se aprecia en la tabla 2, al estudiar la variable sobre el número de veces atendidas en el centro $47.0 \%$ fue atendida una vez y $53.0 \%$ varias veces.

Muchas embarazadas no asisten a la consulta estomatológica en el primer trimestre porque alegan sentir miedo, otras desconocen su importancia. En estudios previamente citados por la autora, ${ }^{11}$ se revela que el $47 \%$ de las embarazadas estudiadas, presentaron escasa información respecto a 
que las enfermedades bucales más frecuentes estuvieran asociadas a los cambios fisiológicos, anatómicos y psicológicos, que tienen lugar en la mujer durante el embarazo. Por otra parte, gran cantidad desconocen los motivos del deterioro dental en esta etapa, aunque algunas de ellas identifican la insuficiente higiene dental, el excesivo consumo de dulces y los cambios hormonales como factores causales de las caries dentales y del sangrado gingival. Estos resultados se corresponden con los descritos por Goepel, Bowsher, citados por Nastri. ${ }^{12}$

Es aconsejable realizar visitas periódicas al odontólogo, según lo establece el programa de atención mediante el cual se puede detectar y efectuar los tratamientos oportunos, así como, prevenir cualquier alteración para que la salud bucal sea óptima, llevando una buena comunicación interpersonal con la gestante para proporcionarle promoción y educación para la salud.

En la boca existen proporciones relativas de bacterias: existe una proporción de bacterias importantes asociadas a salud, las cuales predominan sobre bacterias potencialmente patógenas que causan las caries y la enfermedad de las encías. Cuando se produce el desbalance en estas familias de bacterias predominan las dañinas, las cuales crecen maduran y se organizan favoreciendo la aparición de problemas en la boca. ${ }^{13}$

Precisamente, el cepillado de los dientes tiene por objetivo evitar que las bacterias maduren y se desarrollen en el tiempo, evitando así la aparición de enfermedades. ${ }^{13}$

Tabla 3: Frecuencia del cepillado

\begin{tabular}{|c|c|c|c|}
\hline & Veces de Cepillado & $\mathbf{N}^{\mathbf{0}}$ de Pacientes & $\%$ \\
\hline a) & $\bullet$ Una Vez & 30 & 35 \\
\hline b) & $\bullet \quad$ Dos Veces & 50 & 53 \\
\hline c) & $\bullet \quad$ Tres Veces & 15 & 12 \\
\hline & Total & 95 & 100 \\
\hline
\end{tabular}


Del total de mujeres embarazadas examinadas (tabla 3), $35 \%$ la frecuencia del cepillado era una vez, dos veces (53.0\%), tres veces $12.0 \%$. El $68.0 \%$ usa el hilo dental.

La deficiencia del cepillado se relaciona fundamentalmente con dos motivos: las náuseas que produce la práctica de este hábito, porque la embarazada se ve asediada por la sintomatología propia de este estado, lo que contribuye a la acumulación de placa dentobacteriana, con bacterias organizadas y adheridas a ella sobre la superficie del diente. Con todos estos factores interactuando entre sí, la caries dental logra establecerse, y llega a producir, en algunos casos, la mortalidad dentaria. ${ }^{14}$

La atención odontológica se convierte en prioridad, si se tiene en cuenta que existe una estrecha relación entre la salud bucal y el embarazo con un dinamismo directamente proporcional entre estos dos aspectos: la salud bucal inadecuada puede afectar el buen desarrollo del embarazo y, a su vez, el embarazo puede afectar la salud bucal de la gestante. ${ }^{14}$

La modificación de la conducta individual con el fin de reducir el riesgo de enfermar, o de aumentar la salud y el bienestar, es hoy el objetivo común de las diferentes concepciones de la salud pública, donde la promoción de salud con su herramienta fundamental, la educación para la salud, juega un papel trascendental. ${ }^{14}$

Tabla 4: Indicación del odontólogo de las patologías bucodentales en las embarazadas

\begin{tabular}{|c|c|c|c|}
\hline & Opción & N$^{\circ}$ DE PACIENTES & $\%$ \\
\hline a) & Si & 49 & 51 \\
\hline b) & No & 46 & 49 \\
\hline & Total & 95 & 100 \\
\hline
\end{tabular}

Respecto a las indicaciones del odontólogo acerca de las patologías bucales en las embarazadas (tabla 4), 51.0\% plantearon haber recibido indicaciones por parte del personal médico, mientras el $49.0 \%$ dijo lo contrario. 
Las causas por las que no se llevan las recomendaciones del odontólogo a cabo fueron debidas a problema económicos, familiares o no le interesaron.

El nivel de educación para la salud bucal se encuentra en estrecha relación con la caries dental y las periodontopatías. En la investigación se revela que las embarazadas estudiadas presentaron insuficiente información respecto a las enfermedades bucales más frecuentes asociadas a los cambios fisiológicos, anatómicos y psicológicos que tienen lugar en la mujer durante el embarazo. Por otra parte, gran cantidad de gestantes desconocen los motivos del deterioro dental en esta etapa, aunque algunas de ellas identifican la deficiente higiene dental, el excesivo consumo de dulces y los cambios hormonales como factores causales de las caries dentales y del sangrado gingival. Estos resultados corresponden con los descritos citados por Rodríguez Lezcano Aliet acerca de factores de riesgo y enfermedades bucales en gestantes. ${ }^{15}$

\section{Conclusiones}

Se concluye que en nuestras embarazadas predominó la caries dental, seguida de la periodontitis, la higiene bucal deficiente fue el factor de riesgo que más influyó. De este estudio se infirió que la realización de trabajos educativos, dirigidos a mejorar el estado de salud bucal constituye una necesidad del momento actual.

\section{Referencias bibliográficas}

1- González Naya G, Montero del Catillo ME. Estomatología General Integral. La Habana: Ciencias Médicas; 2013.

2- Gómez Porcegué Y, Macías Estrada L. Salud Bucal en un grupo de Embarazadas. Área Sur. Sancti Spíritus. Gac Méd Espirit. 2015 [citado 15 julio 2016]; 17(3): 48-55. Disponible en: http://scieloprueba.sld.cu/scielo.php?script=sci_arttext\&pid=S1608$89212015000300008 \& \operatorname{lng}=\mathrm{es}$.

3- Tamayo Ávila Y. Enfermedad periodontal en embarazadas atendidas en la Clínica Estomatológica Manuel Angulo Farrán. CCM. 2013 [citado 15 julio 2016]; 17(1 supl 1) Disponible en: http://www.revcocmed.sld.cu/index.php/cocmed/article/view/1238/279 
4 Nápoles García D, Nápoles Méndez D, Moráguez Perelló G, Cano García VM, Montes de Oca García A. Estado de salud periodontal en embarazadas. MEDISAN .2012 [citado 15 julio 2016]; 16(3): 333-340. Disponible en:

http://scieloprueba.sld.cu/scielo.php?script=sci_arttext\&pid=S1029-

$30192012000300004 \& \operatorname{lng}=\mathrm{es}$

5- Méndez de Varona Yuliet B, Batista Sánchez Tamara, Peña Marrero Yamilet, Torres Acosta Raúl. Principales enfermedades bucodentales en embarazadas. ccm [Internet]. 2016 [citado 15 julio 2016]; 20 (4): 702-713. Disponible en: http://scielo.sld.cu/scielo.php?script=sci_arttext\&pid=S1560-43812016000400009\&lng=es

6- Ministerio de salud pública del ecuador Normalización del sistema nacional de salud Área de salud bucal. 2009. [citado 15 julio 2016] Disponible en: https://aplicaciones.msp.gob.ec/.../NORMAS\%20Y\%20PROCEDIMIENTOS\%20DE\%...

7- Panadés Alsina L, Calvo X. La importancia de un buen consejo en salud bucodental durante el embarazo Matronas 2014 [citado 15 julio 2016]; 15(3): 73-74 Disponible en: www.federacion-matronas.org/.../articulo-especial-salud-bucal-y-embarazo-1.pdf

8- Garcia Morales G, Vega Vega S, Tolentino Alvarado A, 2016. Prevalencia de enfermedad periodontal en embarazadas de una unidad de medicina familiar de Acapulco, Guerrero. [citado 15 julio 2016] Disponible en: http://www.sciencedirect.com/science/article/pii/S1405887116301286

9- De Aguiar T, Valsecki Junior A, Corrêa Da Silva S, Lopez Rosell F, Pereira Da Silva E. Avaliação do perfil de risco de cárie dentária em gestantes de Araraquara, Brasil. Rev Cubana. 2011[Citado 17 julio 2016]; 48(4): Disponible en: http://scielo.sld.cu/scielo.php?script=sci_arttext\&pid=S0034$75072011000400005 \& \operatorname{lng}=\mathrm{es} \& \mathrm{nrm}=\mathrm{iso} \& \operatorname{lng}=\mathrm{pt}$

10- Vera Delgado MV, Martínez Beneyto Y, Pérez Lajarín L, Fernández Guillart A, Maurandi López A. Nivel de salud bucal de la mujer embarazada de la comunidad autónoma de la región de Murcia. Odontología Preventiva [Serie en Internet]. 2010[ citado 15 julio 2016]; 2(1):1-7: Disponible en: http://www.medicinaoral.com/preventiva/volumenes/v2i1/01.pdf 
11- Bastarrechea Milián M, Fernández Ramírez L, Martínez Naranjo T. La embarazada y su atención estomatológica integral como grupo priorizado. Área de salud Moncada. Revista Cubana Estomatol. 2009; 46(4).

12- Nastri N. La salud bucal en el embarazo: derribando el mito de que cada embarazo cuesta un diente 2009. [citado 15 julio 2016]. Disponible en: http://www.femeninas.com.ar/salud-bucal-durante-el-embarazo.asp

13- Importancia del cepillado. 2013 [citado 15 julio 2016]. Disponible en: http://dental.saludestudiantil.uc.cl/index.php/sabermas?task=verItem\&id_item $=47 \&$ vista=sabermas

14- Bouza Vera Meylín, Martínez Abreu Judit, Carmenate Rodríguez Yamila, Betancourt González Magdalena, García Nicieza Maydelis. El embarazo y la salud bucal. Rev.Med.Electrón. [citado 17 julio 2016]; 38(4): 628-634. Disponible en: http://scielo.sld.cu/scielo.php?script=sci_arttext\&pid=S1684-18242016000400013\&lng=es.

15- Rodríguez Lezcano Aliet, León Valle Mirtha, Arada Otero Arelys, Martínez Ramos Michel. Factores de riesgo y enfermedades bucales en gestantes. Rev Ciencias Médicas 2013 [citado 17 julio 2016]; 17(5): 51-63. Disponible http://scielo.sld.cu/scielo.php?script=sci_arttext\&pid=S1561-31942013000500006\&lng=es. 